\title{
Design of Experiments Assessment for the Determination of Moisture Content in Five Herbal Raw Materials Contained in Tea Products
}

Luis Castillo* 1,2 (0)
Eleaneth Baltodano 1,3
Nils Ramírez 1,3
Rolando Vargas 1,3
Georgia Hanley ${ }^{1}$
1Department of Industrial Pharmacy,
Universidad de Costa Rica, San José,
Costa Rica
'Laboratory of Phytopharmacology and
Pharmaceutical Technology (LAFITEC),
Institute of Pharmaceutical Research
(INIFAR), Universidad de Costa Rica,
San José, Costa Rica
3Laboratory of Biopharmacy and
Pharmacokinetics
Institute of Pharmaceutical Research
(INIFAR), Universidad de Costa Rica,
San José, Costa Rica
*email: luis.castillohenriquez@ucr.ac.cr
Keywords:
Design of Experiments
Herbal product
Quality control
Tea

\begin{abstract}
Research interest in natural raw materials is rapidly growing due to the high demand for natural products like herbal teas. Their quality control has a direct impact on safety and efficacy. The aim of this study was to evaluate the impact of sample's mass and temperature on moisture content in Camellia sinensis (Black tea), Cassia fistula (Senna), Chamaemelum nobile (Chamomille), Lippia alba (Juanilama) and Tilia platyphyllos (Linden) with a gravimetric method developed through a full factorial $3^{2}$ DoE. A response optimizer was executed in order to establish the test conditions that allow obtaining a response according to a target value from a certified method. DoE's ANOVA shows reproducibility for Camellia sinensis, Cassia fistula, and Lippia alba. Also, the method's model is able to explain the response variability for all samples based on the $\mathrm{R}^{2}$ (adj). The composite desirability for the proposed conditions of analysis for the five herbal materials is satisfactory according to each target value. However, the lack of reproducibility in Chamaemelum nobile and Tilia platyphyllos and also, the response prediction problems according to the $\mathrm{R}^{2}$ (pred) for Cassia fistula and Chamaemelum nobile, suggest the execution of further studies for them. Therefore, the present method is considered to be adequate for the analysis of moisture content in Camellia sinensis and Lippia alba raw herbs.
\end{abstract}

Received: January $7^{\text {th }} 2019$

Accepted: February $21^{\text {st }} 2020$

Published: February 27th 2020

(c) 2020 Luis Castillo, Eleaneth Baltodano, Nils Ramírez, Rolando Vargas, Georgia Hanley. Published by Institute for Research and Community Services Universitas Muhammadiyah Palangkaraya. This is an Open Access article under the CC-BY-SA License (http://creativecommons.org/licenses/by-sa/4.0/). DOI: https:// doi.org/10.33084/bjop.v3i1.1236.

\section{INTRODUCTION}

Currently, many plants and herbs are used for the manufacture of natural products and for the synthesis of novel medicines, due to their therapeutic properties. Herbal raw materials are used almost by $80 \%$ of the world population, based on empiric knowledge or ancient traditional medicine (Asghar et al., 2016; Orphanides et al., 2013; Rodino \& Butu, 2019; Singh et al., 2019). The high demand and the fact that herbs also contain toxic substances imply a critical role in quality control of these raw materials, since natural products must fulfill quality, safety and efficacy requirements (Carvalho et al., 2018; Mukherjee, 2019a).

In 1998, the World Health Organization (WHO) published the guideline 'Quality Control Methods for Medicinal Plant Materials', which addresses the need of quality assurance for natural raw materials with the aim of guaranteeing safety of herbal drug products. 
According to this, not only a quantitative analysis of the active compounds has to be done, but also a qualitative analysis in order to evaluate physicochemical characteristics such as color, volatile compounds, ash values, moisture content and even taste and aroma (Mandal et al., 2017; Mukherjee, 2019b; Sahoo et al., 2010; Thomas \& ElSohly, 2016; World Health Organization, 1998).

In this paper, special attention will be given to the moisture content analysis. This physicochemical test provides relevant information on loss on drying and about the presence of an excessive amount of water in the natural raw material, usually expressed as a percentage by weight on a wet basis. Therefore, it is considered as one of the most important parameters for the quality evaluation of crude materials and for the prediction of the material's shelf life, playing a fundamental role from a stability perspective (Mora-Román et al., 2018a; Zambrano et al., 2019).

In the manufacture of herbal drugs, alimentary and natural products; the starting materials are usually represented by fresh whole plants or their parts, which will face different manipulation processes in order to make them a suitable input material. One of these operations is the drying process. Direct drying methods, such as the gravimetric method, determine the moisture content by weighing a sample before and after drying, where all the weight loss is assumed to be explained by the removal of water (Mukherjee, 2019b; Zambrano et al., 2019).

Poor quality control of plants or dried simplicia from tropical and subtropical countries make them more vulnerable to fungal contamination resulting in microbial toxins as well as aflatoxins, which are well known for their carcinogenic activity. In addition to that, excess of moisture in biological materials causes deterioration by hydrolysis. Whereas moisture free crude drugs are more likely to overcome a decomposition reaction, which allows safe storage over an extended period of time and better stability. Since this kind of materials generally contain around $75-80 \%$ of water, some researches have reported that a successful preservation can be achieved if the water levels are lowered until less than $13-15 \%$ (Cheng et al., 2013; Kaur et al., 2014; Mandal et al., 2017; Teles et al., 2012).

However, when working with herbal raw materials it is necessary to define how dry is dry enough. A perfect way of achieving a target value is through Design of Experiments (DoE). Basically, DoE is a statistical tool used for the organization, conduction and interpretation of the results obtained through the execution of a small, but well designed, number of tests, so that useful information can be collected in the most efficient way (Zambrano et al., 2019).

The application of this multivariate analysis technique requires the level establishment of the analyzed factors. Therefore, the selection of an experimental design depends on the previous knowledge and nature of the problem. Moreover, regarding their quality evaluation, independent variables are usually factors of the analytical method, while dependent variables are linked to the properties or parameters that reflect the performance of the raw material or product. As a result, a well-executed study can lead to the identification of the optimal conditions for the operation of a certain process or the best method for an analysis (Djuris et al., 2013).

In the present study, we used DoE to allow the collection and analysis of moisture content data right after the drying process of Camellia sinensis (Black tea), Cassia fistula (Senna), Chamaemelum nobile (Chamomille), Lippia alba (Juanilama) and Tilia platyphyllos (Linden) raw materials used for the manufacture of herbal tea. The first herbal raw material analyzed was Camellia sinensis, which is of great interest for tea consumers due to its several health 
benefits associated with protection against cardiovascular diseases, cognitive performance improvement and body weight regulation. Another herb under study, Cassia fistula, exhibits hepatoprotective, antipyretic and antioxidant activity. Chamaemelum nobile, is traditionally known for its antiseptic and antiinflammatory properties. Lippia alba has several uses in traditional medicine such as antispasmodic, antipyretic, among others. Finally, Tilia platyphyllos is used mostly for its tranquilizing and antiinflamatory properties (Blanco et al., 2013; Conde et al., 2011; Guimarães et al., 2013; Li et al., 2014; Martínez et al., 2009; Nunes et al., 2018; Kumar et al., 2017).

The aim of this study was to evaluate the impact of sample's mass and temperature on moisture content in the five types of herbal raw material. The mentioned DoE consists in $3^{2}$ full factorial design, where it is intended to find the relationship between the temperature of analysis and the required sample's mass for the evaluation of the parameter of interest in a moisture balance. In order to establish the best analytical conditions, the effects of several combinations of the mentioned factors on the moisture content were evaluated and the main effects and interactions were identified for each crude material. Additionally, a response optimizer was executed based on a moisture target value provided by a private quality control laboratory with a certified gravimetric method, which ensures the quality of the herbal raw materials for the manufacture of a physicochemical stable product.

\section{MATERIALS AND METHODS}

\section{Materials}

For the execution of this study it was decided to evaluate the moisture content of the five herbal raw materials shown in Table I, that are commonly used in Costa Rica for the manufacture of herbal teas.

\begin{tabular}{lc}
\hline \multicolumn{1}{c}{ Raw material } & Batch \\
\hline Camellia sinensis (Black tea) & 52009 \\
Cassia fistula (Senna) & $17-01451-1$ \\
Chamaemelum nobile (Chamomille) & 362018 \\
Lippia alba (Juanilama) & ME694 \\
Tilia platyphyllos (Linden) & M711 \\
\hline
\end{tabular}

\section{Equipment}

Dryer/Blender: In-house designed. This machine is made up of an air heating furnace, a drying chamber and net conveyors:

1. Capacity : $: 100 \mathrm{~kg}$

2. Maximum hot air temperature : $90-100^{\circ} \mathrm{C}$

Moisture balance: OHAUS® MB120

1. Capacity : $120 \mathrm{~g}$

2. Precision $: 0.001 \mathrm{~g}$

3. Moisture range : $0.01-100 \%$

4. Heating technology : Halogen

5. Temperature range $: 40-230^{\circ} \mathrm{C}$

\section{Drying/blending phase}

For each herbal raw material, the dryer was filled to approximately a $60 \%$ of its capacity. The operational procedure was according to the in-house method, which establishes a hot air temperature below $90^{\circ} \mathrm{C}$ and a drying time of 7 hours.

\section{Design of experiments}

The DoE was done according to the following:

1. Controlled variables: Drying process and equipment, moisture balance, analyst and raw materials' batches.

2. Non-controlled variables: Previous storage time of the raw materials, initial moisture content, environmental conditions, tests days, and time for the determination of the moisture content in the balance.

3. Input variables and their respective levels: Moisture balance's temperature $\left(100,115\right.$, and $\left.130^{\circ} \mathrm{C}\right)$ and sample's mass $(1,2$, and $3 \mathrm{~g})$.

4. Output variable: Moisture content (\%).

Table I. Herbal raw materials 
5. Type of design: $3^{2}$ full factorial design. The nine treatment combinations for this type of design are shown in the following Table II.

Table II. Organization of the treatments evaluated through the DoE

\begin{tabular}{ccc}
\hline Treatment & Sample's mass $(\mathrm{g})$ & Temperature $\left({ }^{\circ} \mathbf{C}\right)$ \\
\hline 1 & 1 & 100 \\
2 & 1 & 115 \\
3 & 1 & 130 \\
4 & 2 & 100 \\
5 & 2 & 115 \\
6 & 2 & 130 \\
7 & 3 & 100 \\
8 & 3 & 115 \\
9 & 3 & 130 \\
\hline
\end{tabular}

6. Repetitions: Three for each treatment.

7. Runs: twenty-seven for each herbal raw material.

8. Planning and organization of the experimental work: After the drying process, herbal raw materials were transferred to containers under controlled temperature and moisture conditions. Samples for the determination of the moisture content had to be taken from a same container and weighed with 95\% accuracy. The analysis of the 27 samples was randomized.

9. Results interpretation: The statistical analysis of the results was done using Minitab $19 \AA$ software, through a one-way ANOVA (analysis of variance) for the means of the factors under study (Ho: The means are the same, Ha: At least one of the means is significantly different), whose level of significance was $95 \%(a=0.05)$. Factors that significantly influenced the response variable $(\mathrm{P}$ value $<0.05$ ) where identified as well as the presented interactions. The verification of the ANOVA assumptions (normality, constant variance and independence of the residuals) compliance was carried out by using graphical methods. A response optimizer was executed, based on a moisture target value for each herbal raw material, provided by a private quality control laboratory with a gravimetric drying method for human consumption products, certified under the standard of INTE-ISO/IEC 17025:2017.

\section{RESULTS AND DISCUSSION}

Pharmaceutical analysis is an important approach to develop novel analytical and control methodologies for the quality assessment of herbal products. In pharmaceutical and food industries such as the tea one, DoE represents a great tool for the manipulation of factors, facilitating the establishment of specifications based on the results obtained (Djuris et al., 2013; Yang \& Deng, 2016).

As mentioned previously, the selection of an experimental design depends mainly on the nature of the problem and prior knowledge of the phenomenon. However, the design is strongly related to the level of information that is desired to obtain. Every model whether mechanistic or data-based, implies a finite number of factors or input variables related to a response of a certain parameter under study. Therefore, the most common way of obtaining insight of the output variable of interest is by designing and conducting experiments, where a series of observations and measurements lead to the collection of important data (Mukkula \& Paulen, 2019; Gutiérrez-Pulido \& De la Vara Salazar, 2008; Reichert et al., 2019).

Moreover, optimal experimental designs are particularly important in these sciences, since they allow to identify combinations of factors for a proper estimate of the parameters of a model or system. In other words, they can lead to an optimum profile response by selecting the best set of processing conditions. The present DoE is conceived as a $3^{2}$ full factorial design. The presence of a third level for two continuous factors helps to determine a quadratic relationship between the response and both input variables (Harbourne et al., 2009; Mead et al., 2012; Wagner Jr. et al., 2014). 
Despite the number of runs to measure, error will always be present in any study. As the results obtained through the analysis of natural raw materials are influenced in some degree by noise or uncontrolled variables, there must be a strategy for the minimization of the effects caused by them. That's why randomization was employed in this study, because it allows a better statistical distribution of the error attributable to those factors among the results (Castillo-Henríquez et al., 2019a; Mead et al., 2012; Reichert et al., 2019).

\section{Preliminary aspects}

The main objective of this DoE was to establish the best conditions for the determination of the moisture content in herbal raw materials, based on a target value. However, in order to discuss the developed DoE, it must be addressed based on the previous operations that led to the definition of the input variables and the response of interest, even though those processes are not part of the design. The investigation's flow diagram is presented in Figure 1.

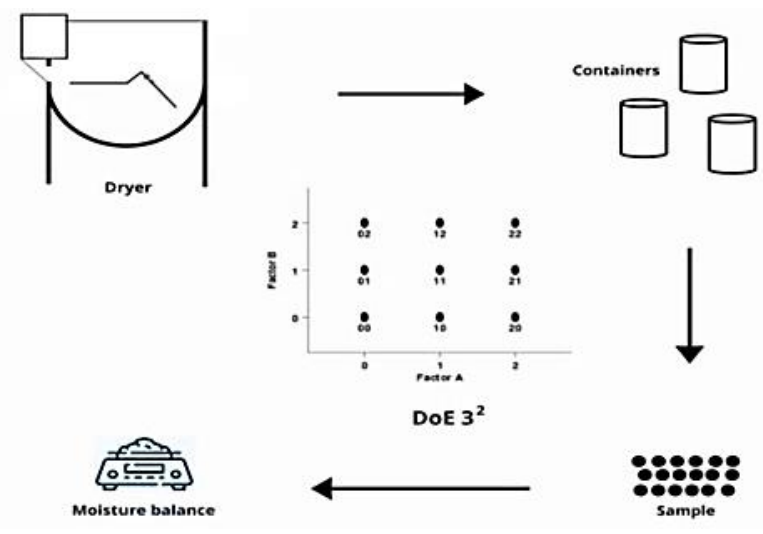

Figure 1. Investigation's flow diagram

As can be seen in the flow diagram presented in Figure 1, initially we have the drying and blending process. Drying is the most critical operation since it has been found that many of the enzymes responsible of the decomposition of natural raw materials are able to survive this process. Also, moisture in herbal drugs causes the reactivation of enzymes, resulting into the loss of active compounds and representing a risk for human health due to fungal proliferation. Some investigations state that above $55^{\circ} \mathrm{C}$ it is possible to inactive the enzymes. Therefore, in this step it is vital to reduce the moisture content level below the limits established for the raw material in the official pharmacopoeias, such as the United States Pharmacopoeia (USP), Mexican Herbalist Pharmacopoeia, or Indian Ayurvedic. However, drying temperature can't be too high (more than $130^{\circ} \mathrm{C}$ ), otherwise antioxidant components and herbs' physical attributes may be affected (Mora-Román et al., 2018b; Steinhoff, 2019; Vargas \& Vecchietti, 2016).

Drying process is not only correlated to safety, but it is also strongly linked to the stability of the pigments or colors from the crude drugs. As a result of that, we chose to work with temperatures from $100-130^{\circ} \mathrm{C}$ in the moisture balance, so we can measure the variable of interest and determine if this is a significant factor, without burning the sample or causing a great loss of volatile substances (Krempski-Smejda et al., 2015; Mizukami et al., 2006; Toontom et al., 2012).

On the other hand, blending has a great impact on the homogeneity of moisture distribution among the whole crude drug that is being processed. That is explained basically because only the region that is in contact with the heated air flow is suffering the removal of moisture or water, while the other sections are stuck to each other and are transferring their moisture. In addition to that, individual parts of herbs used for the manufacture of tea products vary in shape, size and consistency, so it is reasonable to find differences in terms of moisture content. As a consequence, we addressed that situation by analyzing three different amounts of mass consisting of 1,2 , and $3 \mathrm{~g}$, with the aim of determining whether this factor is significant, and to reduce waste as well (Chan et al., 2012; Fomeni, 2018; Schinabeck et al., 2019). 


\section{Analysis of variance}

Now that the study factors are defined, the DoE's main statistical method for the evaluation of their effects and interactions on the desired response is the ANOVA. It is useful for determining whether a term has a significant effect on the output or not. In ANOVA, the random error term accounts for the rest of the effects that can't be explained (Gutiérrez-Pulido \& De la Vara Salazar, 2008; Harbourne et al., 2009; Mukherjee, 2019c).

Nevertheless, in order to do the previous, it is necessary to analyze the P value. This statistic allows to evaluate the significance of the experiment. It indicates the probability that the effect caused by a factor or another term is exclusively due to a random event. However, the smaller it gets means that it is less likely to be explained by a random chance, thus it becomes more significant. For the present DoE the level of significance used was 0.05 . In this model, when a significant difference is detected for the block term, means that an average value from a determine treatment was statistically different among each replica (Gutiérrez-Pulido \& De la Vara Salazar, 2008; Harbourne et al., 2009).

The ANOVA's validity of the results is subjected to the compliance of the model assumptions: normality, equality of variances and independence of residuals. In order to guarantee that, DoE's basic principles were applied: replication, randomization and blocking. The assumptions are commonly verified through the residuals which are generated by the difference between the observed response and the one predicted by the model in each experiment. Also, their verification could need analytical tests, but graphical methods, such as the ones presented in this paper, are accepted as well (Castillo-Henríquez et al., 2019b; Gutiérrez-Pulido \& De la Vara Salazar, 2008). Analysis of variance's summary for moisture content evaluated in herbal raw materials under study is presented in Table III, while residual plots for moisture content in Camellia sinensis, Cassia fistula, Chamaemelum nobile, Lippia alba, and Tilia platyphyllos are presented in Figure 2 to 6, respectively.

Table III. Analysis of variance's summary for moisture content evaluated in herbal raw materials under study

\begin{tabular}{|c|c|c|c|c|c|}
\hline \multirow[b]{2}{*}{ Term } & \multicolumn{5}{|c|}{$P$ value } \\
\hline & 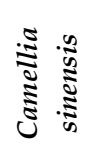 & 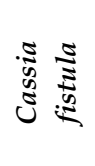 & 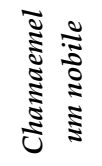 & 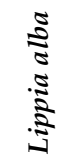 & 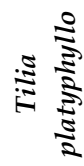 \\
\hline Blocks & 0.101 & 0.992 & 0.011 & 0.737 & 0.003 \\
\hline Sample's mass & 0.000 & 0.005 & 0.001 & 0.000 & 0.000 \\
\hline Temperature & 0.000 & 0.000 & 0.000 & 0.000 & 0.000 \\
\hline $\begin{array}{c}\text { Sample's mass * } \\
\text { Temperature }\end{array}$ & 0.003 & 0.561 & 0.516 & 0.755 & 0.043 \\
\hline
\end{tabular}
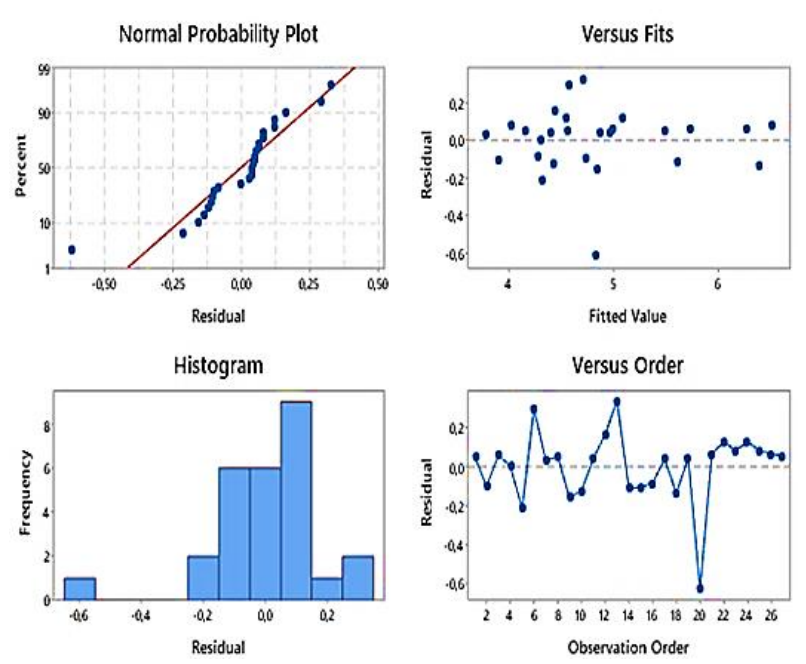

Figure 2. Residual plots for moisture content in Camellia sinensis
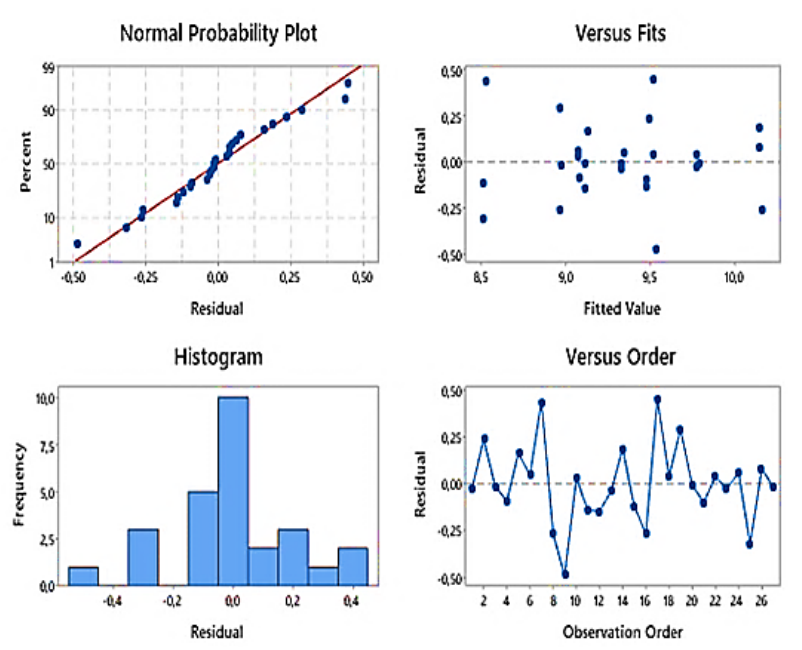

Figure 3. Residual plots for moisture content in Cassia fistula 

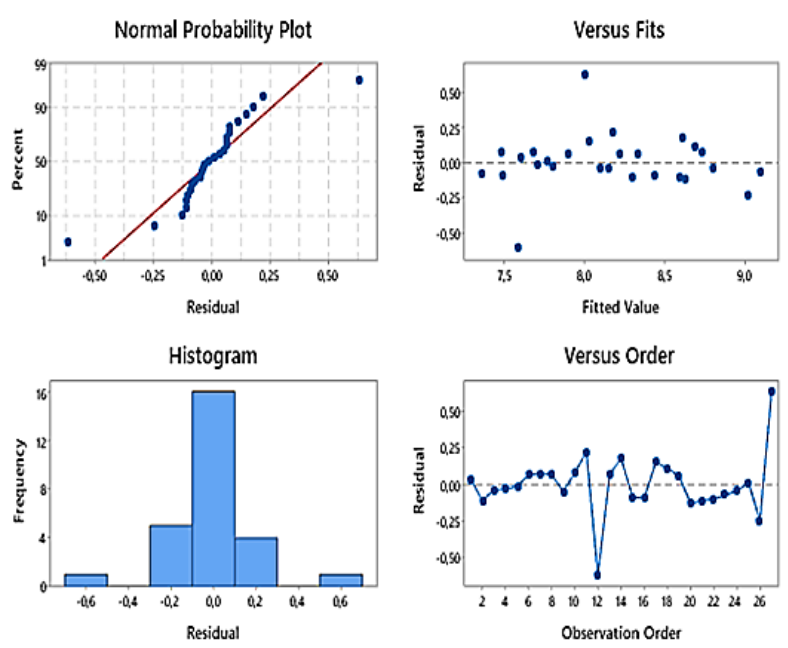

Figure 4. Residual plots for moisture content in Chamaemelum nobile
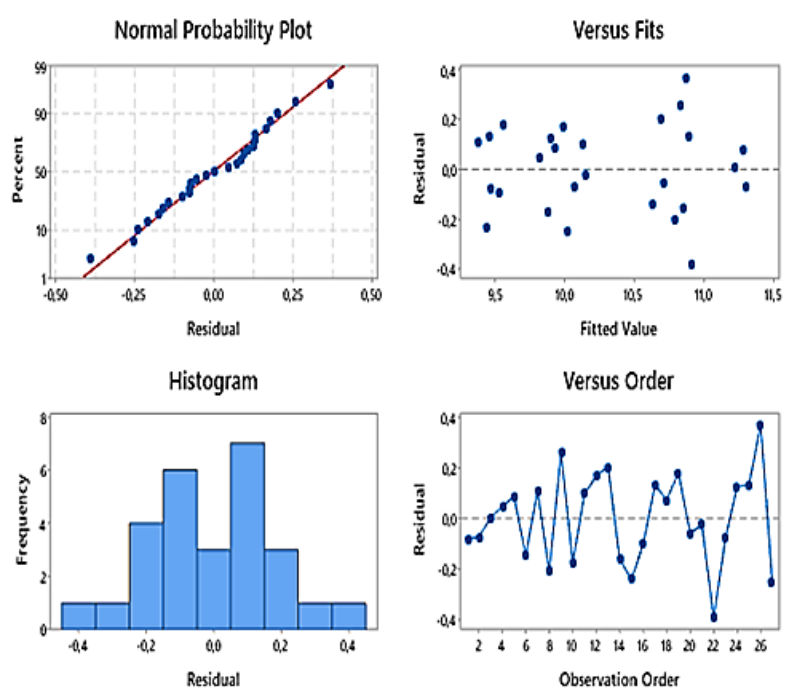

Figure 5. Residual plots for moisture content in Lippia alba
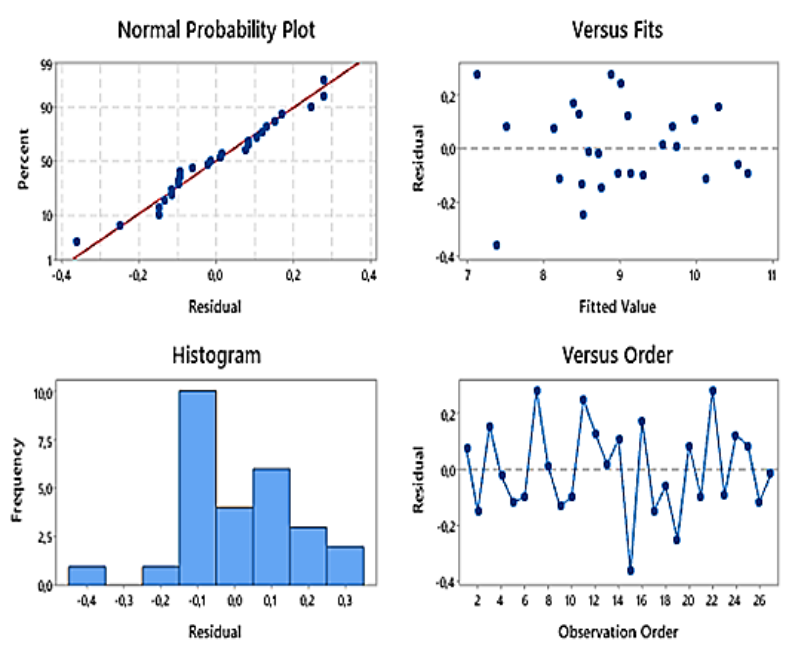

Figure 6. Residual plots for moisture content in Tilia platyphyllos
In the first assumption residuals are expected to follow a normal distribution with zero mean, which means that they tend to be relatively aligned to the straight line. If that behavior is not observed in the graphical method, then the assumption is not satisfied. The second one indicates that the residuals of each treatment have the same variance and it is graphically verified if the points are randomly distributed when the predicted values are located on the $\mathrm{x}$-axis and the residuals are on the $\mathrm{y}$-axis. The third and final assumption states that residuals are independent of each other. The previous can be corroborated by representing the order in which a sample was collected or analyzed, against its respective residual. In such situation, if a pattern is shown when plotting the observation order on the independent axis and the residuals on the dependent axis, then there is a correlation between the errors which clearly doesn't meet the assumption. As can be seen in Figure 2 to 6, all the experiments fulfill the requirements of the ANOVA (Castillo-Henríquez et al., 2019b; Gutiérrez-Pulido \& De la Vara Salazar, 2008).

At this point is important to make reference to the graphical definition of effect of a factor and the main effect. A factor's effect is conceived as the change observed in the response variable due to a level change in the factor. On the other hand, the main effect is equal to the average response observed at the highest level of a factor minus the average response at the lowest one (Djuris et al., 2013; Lin et al., 2011). The relationship curve of sample's mass and temperature's main effects plot for moisture content in Camellia sinensis, Cassia fistula, Chamaemelum nobile, Lippia alba, and Tilia platyphyllos are presented in Figure 7. 
a.

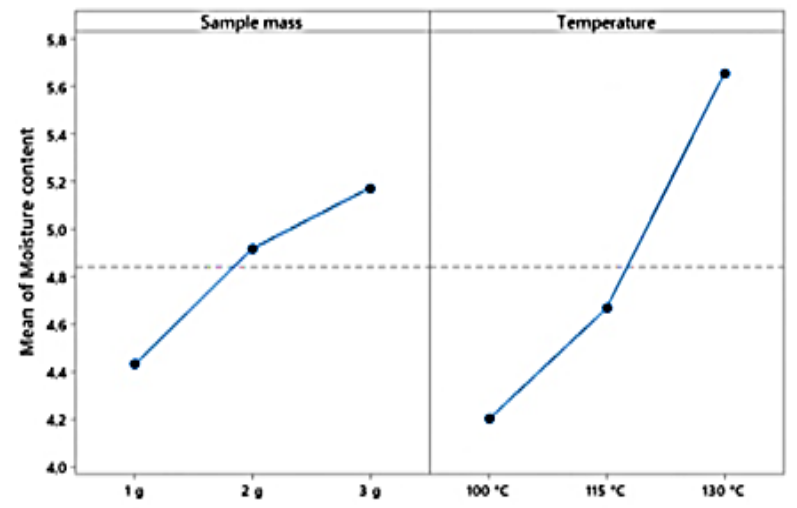

b.

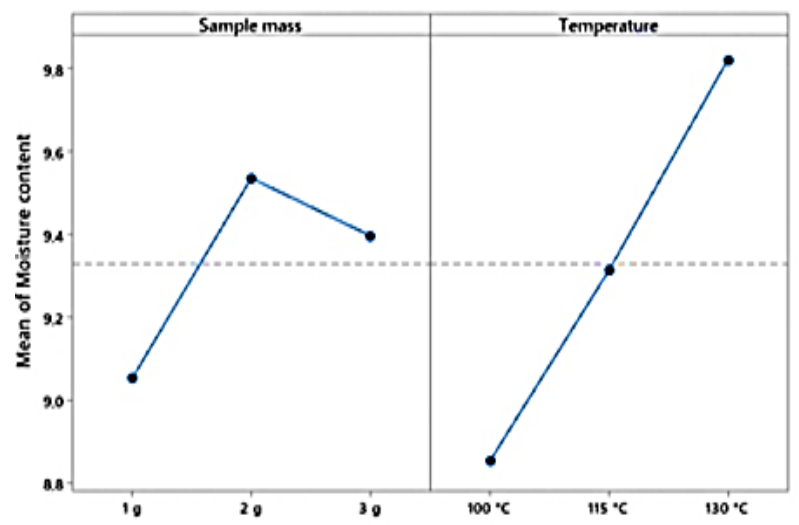

c.

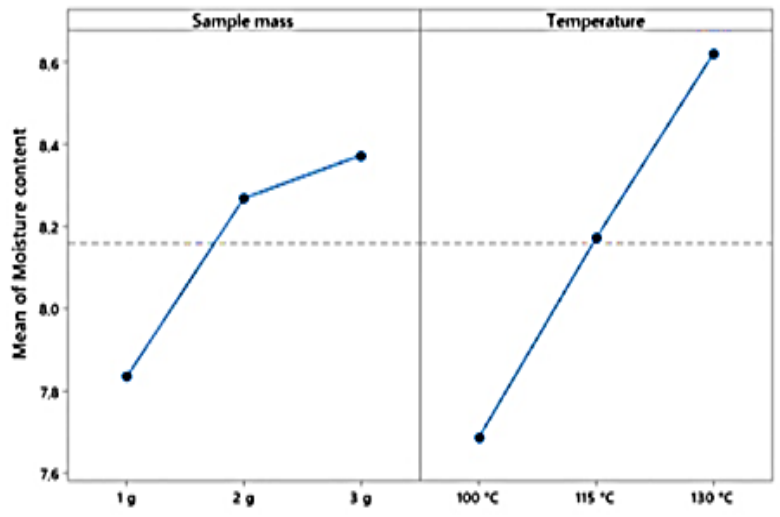

d.

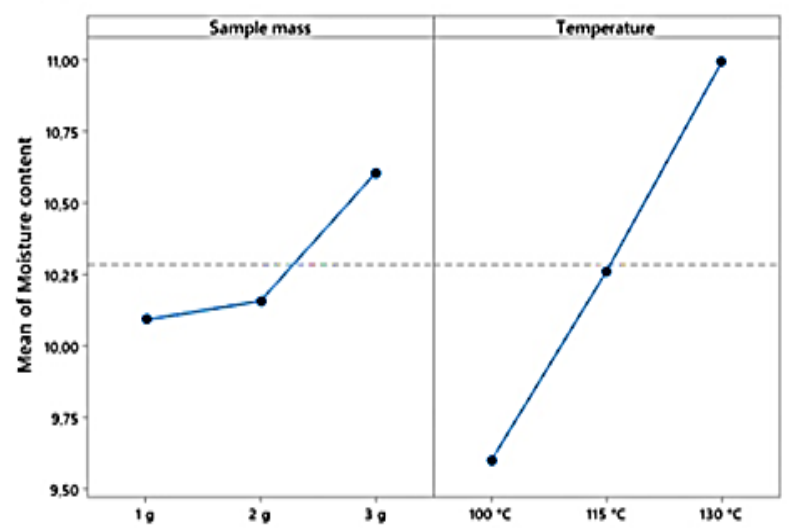

e.

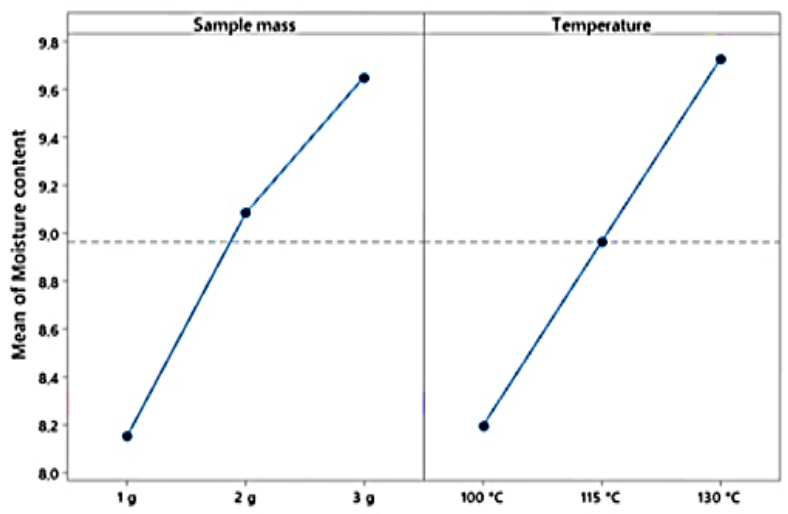

Figure 7. Sample's mass and temperature's main effects plot for moisture content in (a) Camellia sinensis, (b) Cassia fistula, (c) Chamaemelum nobile, (d) Lippia alba, and (e) Tilia platyphyllos

Figure 7 shows the main effects diagram for the moisture content in herbal raw materials under study, where the factors' levels are located in the horizontal axis and the average of the response observed according to each level is in the vertical. According to that figure, in all cases temperature has the main effect on the moisture content mean since the difference in its average responses is greater than the one from sample's mass.

The first herbal raw material analyzed was Camellia sinensis. In this case as can be seen in Table III, blocks are not significant, so the method for this herbal represents a good reproducibility. In contrast, both factors and the interaction between them have values lower than 0.05 , thus they are significant. However, for situations like this when an interaction is presented, no matter how many terms are statistically different; the interaction is the one that will govern the effect on the response. Whereas, it is said that two factors interact significantly on the response variable when the effect of one depends on the level at which the other one is (Lin et al., 2015; Megías-Pérez et al., 2019).

According to the ANOVA on Table III, only the sample's mass and temperature are significant terms in Cassia fistula's model, where no interaction between the factors and the response was detected. On the other 
hand, Chamaemelum nobile presented a $\mathrm{P}$ value for both factors under study below 0.05 , so they are significant. Additionally, the blocks' term is also significant, which means that the method is not reproducible in this herbal raw material (Gutiérrez-Pulido \& De la Vara Salazar, 2008).

The analysis for Lippia alba revealed a significance for both factors; sample's mass and temperature of analysis. The last ANOVA executed for the evaluation of moisture content in Tilia platyphyllos considers all the terms as statistically different. Therefore, the method does not show reproducibility when using this herbal material, like it happened with Chamaemelum nobile. In addition to that, the interaction between the factors will overshadow the effect on the moisture content from the individual ones (Castillo-Henríquez et al., 2019b).

\section{Response optimizer}

Although ANOVA is the central statistical method, DoE counts with another tool which is the Response optimizer. This function helps to identify the configuration values of the factors that when combined, can optimize an individual response or a set of responses through a minimization, a maximization or a predefined target value for the output. It is especially useful for this study, since it allows to evaluate the impact of the sample's mass and temperature on the moisture content and then indicates the most proper treatment to carry out the method of analysis (Gutiérrez-Pulido \& De la Vara Salazar, 2008; Reichert et al., 2019).

When the optimization is based on a target, upper and lower limits have to be defined. For that purpose, we used the uncertainty from the results of the reference values provided by a private quality control laboratory. However, it is important to take into consideration that these limits affect the composite desirability, which is a parameter that evaluates the way in which the proposed model configuration optimizes a response. The composite desirability has a range of $0-1$, where 1 represents the ideal situation, while 0 indicates that the output variable is outside of the acceptable limits (Gutiérrez-Pulido \& De la Vara Salazar, 2008; Reichert et al., 2019).

An important factor to take into consideration in the optimization design is the weight; this determines how the composite desirability is distributed in the interval between the lower or upper limit and the target value. It is possible to choose between $0.1,1$, or 10 . A value lower than 1 means that less emphasis is placed on the target value, 1 is the neutral configuration which gives the same importance to the target and to the limits and finally, a value higher than 1 emphasizes more on the objective which makes difficult to achieve the optimization. Since the present study involves natural raw materials, there's a certain variability that can't be controlled, so we worked with a weight of 1 (Mead et al., 2012; Wagner Jr. et al., 2014). The summary of DoE's results is presented in Table IV.

Table IV. Summary of DoE's results

\begin{tabular}{|c|c|c|c|c|c|}
\hline Sample & 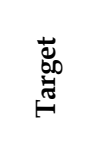 & 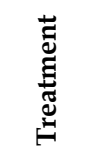 & 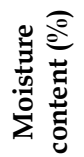 & $\begin{array}{l}\stackrel{\circ}{0} \\
\text { Ŭ }\end{array}$ & 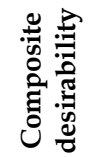 \\
\hline $\begin{array}{l}\text { Camellia } \\
\text { sinensis }\end{array}$ & $\begin{array}{c}3.99 \pm \\
0.19\end{array}$ & $\begin{array}{c}1 \mathrm{~g} ; \\
100^{\circ} \mathrm{C}\end{array}$ & 3.90 & $\begin{array}{l}3.59 ; \\
4.16\end{array}$ & 0.8756 \\
\hline Cassia fistula & $\begin{array}{c}8.87 \pm \\
0.42\end{array}$ & $\begin{array}{c}2 \mathrm{~g} ; \\
100^{\circ} \mathrm{C}\end{array}$ & 8.97 & $\begin{array}{l}8.64 ; \\
9.30\end{array}$ & 0.7698 \\
\hline $\begin{array}{c}\text { Chamaemelum } \\
\text { nobile }\end{array}$ & $\begin{array}{c}7.77 \pm \\
0.38\end{array}$ & $\begin{array}{c}1 \mathrm{~g} ; \\
115^{\circ} \mathrm{C}\end{array}$ & 7.76 & $\begin{array}{l}7.45 \\
8.08\end{array}$ & 0.9825 \\
\hline Lippia alba & $\begin{array}{c}9.98 \pm \\
0.49\end{array}$ & $\begin{array}{c}1 \mathrm{~g} ; \\
115^{\circ} \mathrm{C}\end{array}$ & 9.98 & $\begin{array}{l}9.70 \\
10.26\end{array}$ & 1.0000 \\
\hline $\begin{array}{c}\text { Tilia } \\
\text { platyphyllos }\end{array}$ & $\begin{array}{c}8.42 \pm \\
0.40\end{array}$ & $\begin{array}{c}1 \mathrm{~g} ; \\
115^{\circ} \mathrm{C}\end{array}$ & 8.42 & $\begin{array}{l}8.17 \\
8.67\end{array}$ & 1.0000 \\
\hline
\end{tabular}

As can be seen in Table IV, it was possible to define the most proper treatment for all the herbal raw, for which the composite desirability presents values greater than 0.70. Moreover, for Lippia alba and Tilia platyphyllos a value of 1.0000 was reached, representing a complete fulfillment of the target value and the established limits. The table also shows the expected moisture content 
under the proposed conditions of analysis based on the best treatment and the respective confidence interval for the response. The relationship curve of moisture content (\%) as a function of the balance's temperature $\left({ }^{\circ} \mathrm{C}\right)$ and sample's mass (g) of Camellia sinensis, Cassia fistula, Chamaemelum nobile, Lippia alba, and Tilia platyphyllos are presented in Figure 8.

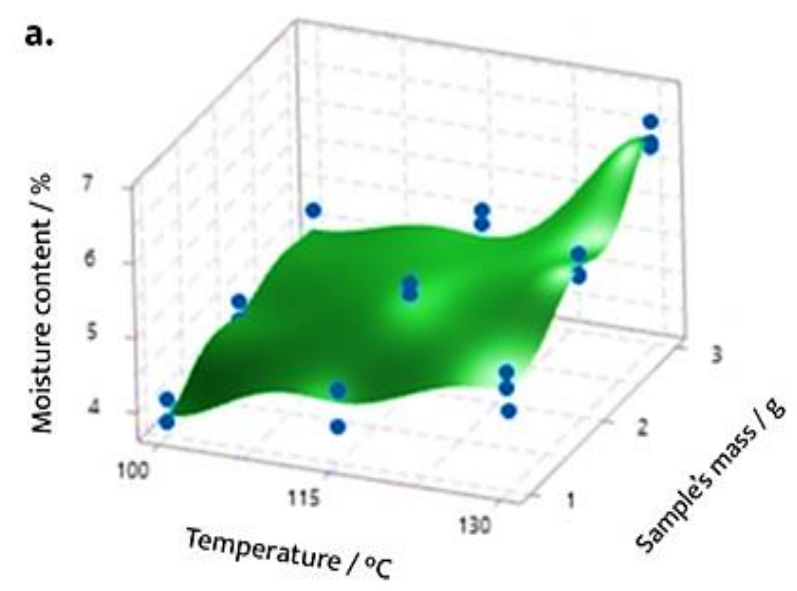

b.
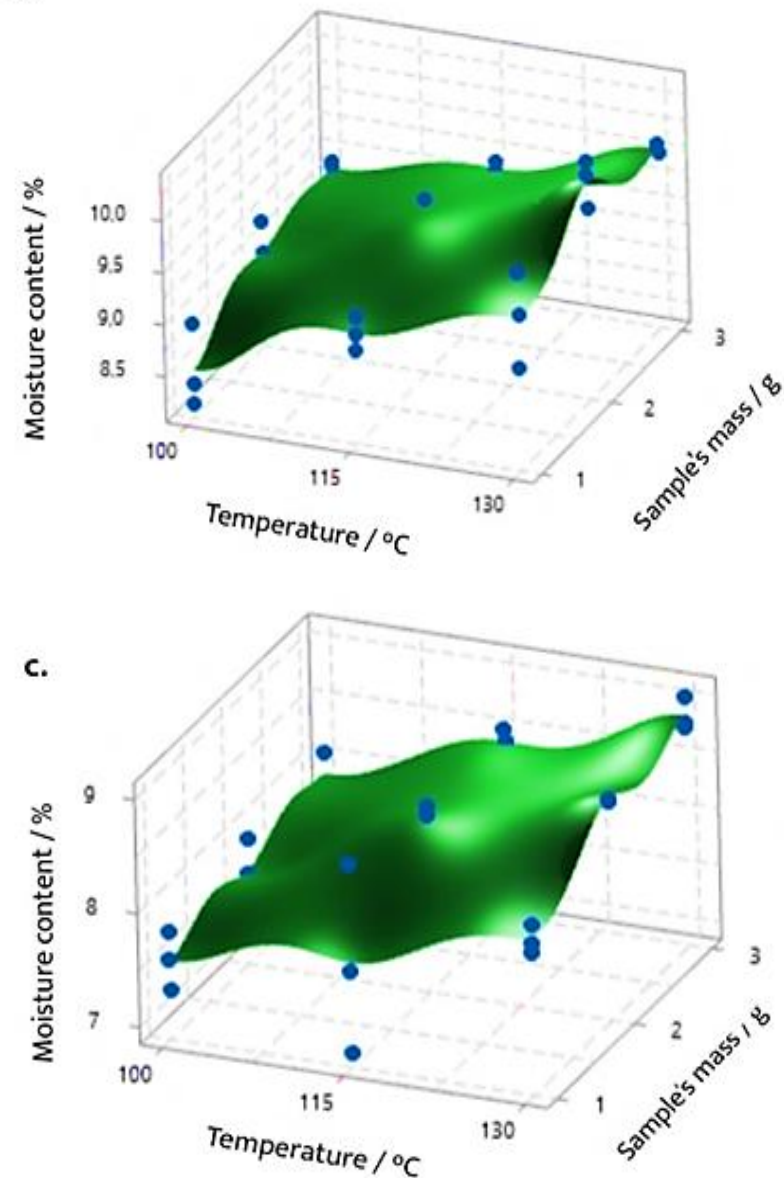
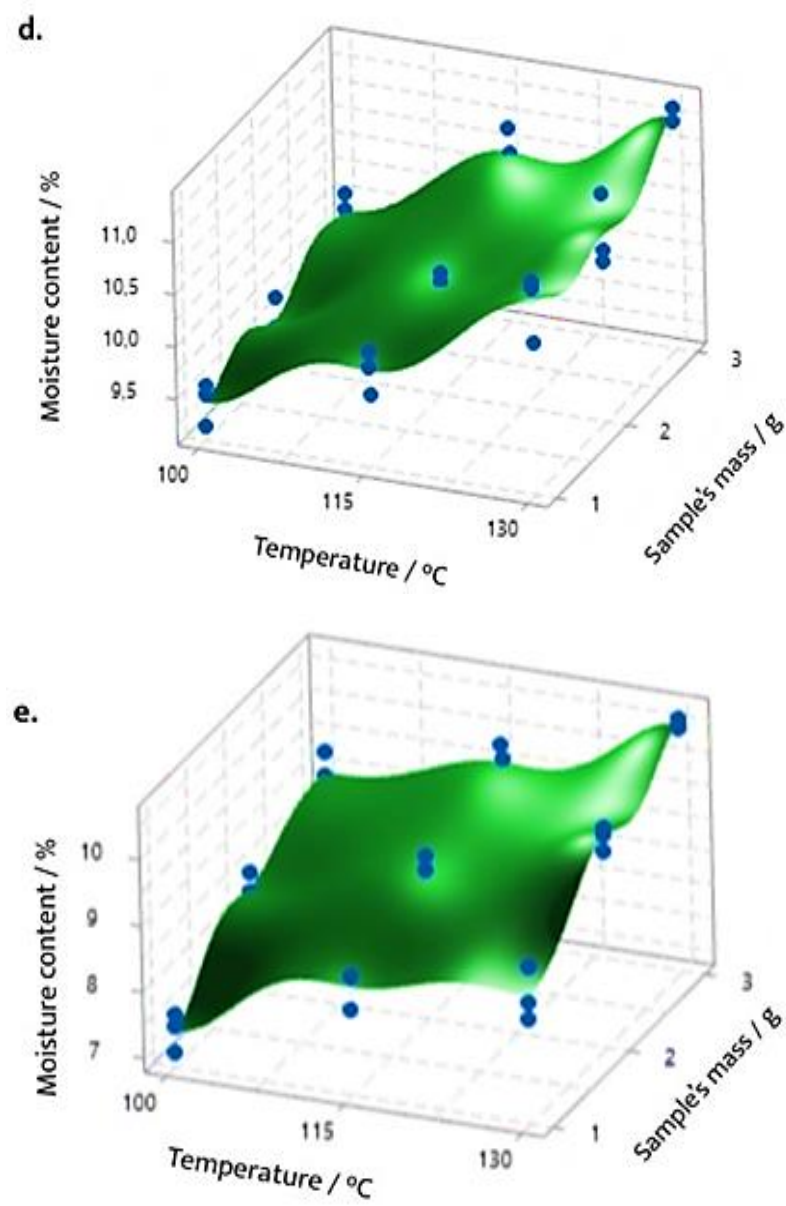

Figure 8. Moisture content (\%) as a function of the balance's temperature $\left({ }^{\circ} \mathrm{C}\right)$ and sample's mass (g) of (a) Camellia sinensis, (b) Cassia fistula, (c) Chamaemelum nobile, (d) Lippia alba, and (e) Tilia platyphyllos

Figure 8 shows the response surface of moisture content (\%) as a function of the balance's temperature and sample's mass for the five herbal materials. This geometrical representation of the response has a center point included for each independent variable along the highest and lowest point, which required three experiments for each output or independent variable (Wagner Jr. et al., 2014).

\section{Model summary}

The correlation coefficient $\left(\mathrm{R}^{2}\right)$ and the adjusted correlation coefficient ( $\mathrm{R}^{2}$ adj) allow to measure the overall quality of the regression model. These coefficients make a comparison of the variability explained by the model against the total variation. In general, for prediction purposes a $\mathrm{R}^{2}$ adj of at least $70 \%$ is 
recommended. Such statistic is preferred over the $R^{2}$ because the latter is falsely increased with each term incorporated into the model (Arvidsson \& Gremyr, 2008). Detailed information about the model summary is presented in Table V.

Table V. Model summary

\begin{tabular}{|c|c|c|c|c|c|}
\hline Term & 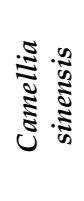 & 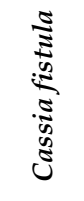 & 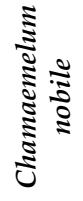 & 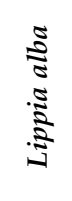 & 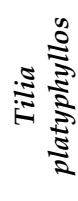 \\
\hline $\mathrm{R}^{2}(\%)$ & 94.47 & 82.77 & 85.86 & 92.66 & 97.11 \\
\hline $\mathrm{R}^{2}$ (adj) (\%) & 91.02 & 72.00 & 77.03 & 88.07 & 95.30 \\
\hline $\mathrm{R}^{2}$ (pred) (\%) & 84.26 & 50.93 & 59.74 & 79.10 & 91.76 \\
\hline
\end{tabular}

According to Table $\mathrm{V}$, all of the $\mathrm{R}^{2}$ adj are good enough to make predictions about the variability of the model. However, the further to a $100 \%$, the more the model is explained by the noise variables. For example, for Cassia fistula a $72.00 \%$ of the moisture content variability can be explained by the model while the rest $28.00 \%$ is attributed to the forces that cause deviation from target.

In addition to that, Table V shows a predictive coefficient of determination ( $\mathrm{R}^{2}$ pred) which allows to make predictions on the response. In order to do that, it is preferred to have a value that is at least $70 \%$. Regarding that, response prediction can only be done for Camellia sinensis, Lippia alba, and Tilia platyphyllos. In the case of Cassia fistula and Chamaemelum nobile, their inability to predict a response may be due to the following reasons (Arvidsson \& Gremyr, 2008):

1. The studied factors do not have the capacity to explain the variations observed in the output or response variable.

2. The levels used to study the factors are too narrow, so the effect on the response when changing from one level to another is small.

3. Factors not studied in the experiment were not kept sufficiently controlled, causing that variation.
4. The experimental and measurement errors were low, but still present.

\section{CONCLUSION}

The worldwide expansion in production and use of natural products like herbal teas has made their quality, efficacy and safety a major concern for the health authorities. As a result, pharmaceutical analysis introduces itself as a solution for the development of novel quality assessment and control methods. The gravimetric method developed through a DoE for the evaluation of the moisture content, showed reproducibility for Camellia sinensis, Cassia fistula, and Lippia alba. An adequate approximation to the target value based on the composite desirability was done for the five herbal materials and the confidence interval for their response was established in order to guarantee a physicochemical parameter for stability. However, the lack of reproducibility in Chamaemelum nobile and Tilia platyphyllos and also, the response prediction problems according to the $\mathrm{R}^{2}$ (pred) for Cassia fistula and Chamaemelum nobile, suggest the execution of further studies for them. Therefore, the present method is considered to be adequate for the analysis of moisture content in Camellia sinensis and Lippia alba raw herbs, for which a robust experimental design is recommended as a final step before its approval.

\section{ACKNOWLEDGMENT}

No potential conflict of interest was reported by the authors.

\section{REFERENCES}

Arvidsson, M. \& Gremyr, I. (2008). Principles of robust design methodology. Quality and Reliability Engineering International, 24(1), 23-35. doi: 10.1002 /qre.864 
Asghar, A., Abdullah, Irshad, M.A., \& Majeed, M. (2016). Elucidating the therapeutic potential of nutraceuticals. In A. Grumezescu (Ed.), Nutraceuticals (pp. 231-270). Massachusetts, United States: Academic Press. doi: 10.1016/B978-0-12-804305-9.00007-5

Blanco, M.A., Colareda, G.A., van Baren, C., Bandoni, A.L., Ringuelet, J., \& Consolini, A.E. (2013). Antispasmodic effects and composition of the essential oils from two South American chemotypes of Lippia alba. Journal of Ethnopharmacology, 149(3), 803-809. doi: 10.1016/j.jep.2013.08.007

Carvalho, P.M.M, Macêdo, C.A.F., Ribeiro, T.F., Silva, A.A., Da Silva, R.E.R., de Morais, L.P., Kerntopf, M.R., Menezes, I.R.A., \& Barbosa, R. (2018). Effect of the Lippia alba (Mill.) N.E. Brown essential oil and its main constituents, citral and limonene, on the tracheal smooth muscle of rats. Biotechnology Reports, 17, 31-34. doi: 10.1016/j.btre.2017.12.002

Castillo-Henríquez, L., Vargas-Zúñiga, R., CarazoBerrocal, G., Madrigal-Redondo, G., CalvoGuzmán, B., \& Baltodano-Viales, E. (2019a). Development of immediate release Rupatadine fumarate $10 \mathrm{mg}$ tablets: A Quality by Design $(\mathrm{QbD})$ approach. Drug Development and Industrial Pharmacy, 45(10), 1674-1681. doi: 10.1080/03639045.2019.1652637

Castillo-Henríquez, L., Madrigal-Redondo, G., VargasZúñiga, R., \& Carazo-Berrocal, G. (2019b). Design of Experiments for the Establishment of the Dissolution Test Conditions of Rupatadine Fumarate $10 \mathrm{mg}$ tablets. Journal of Drug Delivery and Therapeutics, 9(1-s), 331-336. doi: 10.22270/jddt.v9i1-s.2359

Chan, E.W.C., Lye, P.Y., Tan, L.N., Eng, S.Y., Tan, Y.P., \& Wong, Z.C. (2012). Effects of drying method and particle size on the antioxidant properties of leaves and teas of Morus alba, Lagerstroemia speciosa and Thunbergia laurifolia. Chemical Industry and Chemical Engineering Quarterly, 18(3), 465-472. doi: 10.2298/CICEQ111116023C

Cheng, W.C., Ng, C.S., \& Poon, N.L. (2013). Herbal Medicines and Phytopharmaceuticals Contaminations. In J. Siegel, P. Saukko, \& M. Houck (Eds.), Encyclopedia of Forensic Sciences. $2^{\text {nd }}$ edition (pp. 280-288). Amsterdam,
Netherlands: Elsevier. doi: 10.1016/B978-0-12382165-2.00318-4

Conde, R., Corrêa, V.S.C., Carmona, F., Contini, S.H.T., \& Pereira, A.M.S. (2011). Chemical composition and therapeutic effects of Lippia alba (Mill.) $\mathrm{N}$. E. Brown leaves hydro-alcoholic extract in patients with migraine. Phytomedicine: International Journal of Phytotherapy and Phytopharmacology, 18(14), 1197-1201. doi: 10.1016/j.phymed.2011.06.016

Djuris, J., Ibric, S., \& Djuric, Z. (2013). Experimental design application and interpretation in pharmaceutical technology. In J. Djuris (Ed.), Computer-Aided Applications in Pharmacentical Technology (pp. 31-56). Cambridge, England: Woodhead Publishing. doi: 10.1533/9781908818324.31

Fomeni, F.D. (2018). A multi-objective optimization approach for the blending problem in the tea industry. International Journal of Production Economics, 205, 179-192. doi: 10.1016/j.ijpe.2018.08.036

Guimarães, R., Barros, L., Dueñas, M., Calhelha, R.C., Carvalho, A.M., Santos-Buelga, C., Queiroz, M.J.R.P., \& Ferreira, I.C.F.R. (2013). Nutrients, phytochemicals and bioactivity of wild Roman chamomile: A comparison between the herb and its preparations. Food Chemistry, 136(2), 718-725. doi: 10.1016/j.foodchem.2012.08.025

Gutiérrez-Pulido, H. \& De la Vara-Salazar, R. (2008). Análisis y diseño de experimentos Segunda edición. Santa Fe, México: McGrawHill Interamericana.

Harbourne, N., Jacquier, J.C., \& O'Riordan, D. (2009). Optimization of the extraction and processing conditions of chamomile (Matricaria chamomilla L.) for incorporation into a beverage. Food Chemistry, 115(1), 15-19. doi: 10.1016/j.foodchem.2008.11.044

Kaur, L., Jayasekera, S., \& Moughan, P.J. (2014). Antioxidant Quality of Tea (Camellia sinensis) as Affected by Environmental Factors. In V. Preedy (Ed.), Processing and Impact on Antioxidants in Beverages (pp. 121-129). Massachusetts, United States: Academic Press. doi: 10.1016/B978-0-12-404738-9.00013-1

Krempski-Smejda, M., Stawczyk, J., Śmigielski, K., \& Prusinowska, R. (2015). Drying of Herbal 
Product in Closed System. Drying Technology, 33(13), 1671-1677. doi: 10.1080/07373937.2015.1066384

Kumar, A.K., Satish, S., Sayeed, I., \& Hedge, K. (2017). Therapeutic Uses of Cassia Fistula: Review. International Journal of Pharma and Chemical Research, 3(1), 38-43.

Li, S., Li, S.K., Li, H.B., Xu, X.R., Deng, G.F., \& Xu, D.P. (2014). Antioxidant Capacities of Herbal Infusions. In V. Preedy (Ed.), Processing and Impact on Antioxidants in Beverages (pp. 41-50). Massachusetts, United States: Academic Press. doi: 10.1016/B978-0-12-404738-9.00005-2

Lin, X., Chen, Z., Zhang, Y., Luo, W., Tang, H., Deng, B., \& Li, B. (2015). Comparative characterization of green tea and black tea cream: Physicochemical and phytochemical nature. Food Chemistry, 173, 432-440. doi: 10.1016/j.foodchem.2014.10.048

Lin, J., Lu, Z., Yang, H., \& Wang, P. (2011). A design of experiments assessment of moisture content in uncured adhesive on static strength of adhesive-bonded galvanized SAE1006 steel. International Journal of Adhesion and Adhesives, 31(6), 478-485. doi: 10.1016/j.jjadhadh.2011.04.001

Mandal, M., Misra, D., Ghosh, N.N., \& Mandal, V. (2017). Physicochemical and elemental studies of Hydrocotyle javanica Thunb. For standardization as herbal drug. Asian Pacific Journal of Tropical Biomedicine, 7(11), 979-986. doi: 10.1016/j.apjtb.2017.10.001

Martínez, A.L., González-Trujano, M.E., AguirreHernándeza, E., Moreno, J., Soto-Hernández, M., \& López-Muñoz, F.J. (2009). Antinociceptive activity of Tilia americana var. Mexicana inflorescences and quercetin in the formalin test and in an arthritic pain model in rats. Neuropharmacology, 56(2), 564-571. doi: 10.1016/j.neuropharm.2008.10.010

Mead, R., Gilmour, S.G., \& Mead, A. (2012). Statistical Principles for the Design of Experiments: Applications to Real Experiments. Cambridge, United Kingdom: Cambridge University Press. doi: 10.1017/CBO9781139020879

Megías-Pérez, R., Shevchuk, A., Zemedie, Y., \& Kuhnert, N. (2019). Characterization of commercial green tea leaves by the analysis of low molecular weight carbohydrates and other quality indicators. Food Chemistry, 290, 159-167. doi: 10.1016/j.foodchem.2019.03.069

Mizukami, Y., Sawai, Y., \& Yamaguchi, Y. (2006). Moisture Content Measurement of Tea Leaves by Electrical Impedance and Capacitance. Biosystems Engineering, 93(3), 293-299. doi: 10.1016/j.biosystemseng.2005.12.009

Mora-Román, J.J., Agüero-Brenes, N., Angulo-Morales, C., Castro-Solís, J., Hidalgo-Carrillo, G., van Hoof-Gómez, M., Loría-Gutiérrez, A., \& Blanco-Barrantes, J. (2018a). Physicochemical and Microbiological Assays for Quality Evaluation of a Brand of Mentha piperita Tisanes in Costa Rica Market: Employment of the Central American Technical Regulation. Journal of Drug Delivery and Therapeutics, 8(5), 329-337. doi: 10.22270/jddt.v8i5.1878

Mora-Román, J.J., Alvarado-Fernández, M. J., ApúLeitón, N., Arroyo-Solórzano, J. D., EspeletaGonzález, D., Piedra-Navarro, H., \& BlancoBarrantes, J. (2018b). Pruebas fisicoquímicas para la evaluación de la calidad de una marca costarricense de tisanas de valeriana. Revista Médica de la Universidad de Costa Rica, 12(1), 1526.

Mukherjee, P.K. (2019a). Quality Evaluation of Herbal Medicines: Challenges and Opportunities. In P.K. Mukherjee (Ed.), Quality Control and Evaluation of Herbal Drugs (pp. 53-77). Amsterdam, Netherlands: Elsevier. doi: 10.1016/B978-0-12-813374-3.00003-X

Mukherjee, P.K. (2019b). Qualitative Analysis for Evaluation of Herbal Drugs. In P.K. Mukherjee (Ed.), Quality Control and Evaluation of Herbal Drugs (pp. 79-149). Amsterdam, Netherlands: Elsevier. doi: 10.1016/B978-0-12-8133743.00004-1

Mukherjee, P.K. (2019c). Safety-Related Quality Issues for the Development of Herbal Drugs. In P.K. Mukherjee (Ed.), Quality Control and Evaluation of Herbal Drugs (pp. 655-683). Amsterdam, Netherlands: Elsevier. doi: 10.1016/B978-0-12813374-3.00018-1

Mukkula, A.R.G. \& Paulen, R. (2019). Optimal experiment design in nonlinear parameter estimation with exact confidence regions. Journal of Process Control, 83, 187-195. doi: 10.1016/j.jprocont.2019.01.004 
Nunes, M.R., Castilho, M.D.S.M., Veeck, A.P.D.L., da Rosa, C.G., Noronha, C.M., Maciel, M.V.O.B, \& Barreto, P.M. (2018). Antioxidant and antimicrobial methylcellulose films containing Lippia alba extract and silver nanoparticles. Carbohydrate Polymers, 192, 37-43. doi: 10.1016/j.carbpol.2018.03.014

Orphanides, A., Goulas, V., \& Gekas, V. (2013). Effect of drying method on the phenolic content and antioxidant capacity of spearmint. Czech Journal of Food Sciences, 31(5), 509-513. doi: 10.17221/526/2012-CJFS

Reichert, I., Olney, P., \& Lahmer, T. (2019). Influence of the error description on model-based design of experiments. Engineering Structures, 193, 100109. doi: 10.1016/j.engstruct.2019.05.002

Rodino, S. \& Butu, M. (2019). Herbal Extracts-New Trends in Functional and Medicinal Beverages. In A. Grumezescu \& A. Holban (Eds.), Functional and Medicinal Beverages (pp. 73-108). Massachusetts, United States: Academic Press. doi: 10.1016/B978-0-12816397-9.00003-0

Sahoo, N., Manchikanti, P., \& Dey, S. (2010). Herbal drugs: Standards and regulation. Fitoterapia, 81(6), 462-471. doi: 10.1016/j.fitote.2010.02.001

Schinabeck, T.M., Weigler, F., Mellmann, J., Idler, C., \& Flöter, E. (2019). Dynamics of the particle moisture distribution during storage of wheat under laboratory and pilot-scale conditions. Journal of Stored Products Research, 82, 54-66. doi: 10.1016/j.jspr.2019.04.001

Singh, V.K., Das, S., Dwivedy, A.K., Rathore, R., \& Dubey, N.K. (2019). Assessment of chemically characterized nanoencapuslated Ocimum sanctum essential oil against aflatoxigenic fungi contaminating herbal raw materials and its novel mode of action as methyglyoxal inhibitor. Postharvest Biology and Technology, 153, 87-95. doi: 10.1016/j.postharvbio.2019.03.022

Steinhoff, B. (2019). Review: Quality of herbal medicinal products: State of the art of purity assessment. Phytomedicine, 60, 153003. doi: 10.1016/j.phymed.2019.153003

Teles, S., Pereira, J.A., Santos, C.H.B., Menezes, R.V., Malheiro, R., Lucchese, A.M., \& Silva, F. (2012). Geographical origin and drying methodology may affect the essential oil of Lippia alba (Mill) N.E. Brown. Industrial Crops and Products, 37(1), 247-252. doi: 10.1016/j.indcrop.2011.12.029

Thomas, B.F. \& ElSohly, M.A. (2016). Analytical Methods in Formulation Development and Manufacturing. In B.F. Thomas \& M. ElSohly (Eds.), The Analytical Chemistry of Cannabis (pp. 63-81). Amsterdam, Netherlands: Elsevier. doi: 10.1016/B978-0-12-804646-3.00004-7

Toontom, N., Meenune, M., Posri, W., \& Lertsiri, S. (2012). Effect of drying method on physical and chemical quality, hotness and volatile flavour characteristics of dried chilli. International Food Research Journal, 19(3), 1023-1031.

Vargas, R. \& Vecchietti, A. (2016). Influence of raw material moisture on the synthesis of black tea production process. Journal of Food Engineering, 173, 76-84. doi: 10.1016/j.jfoodeng.2015.10.043

Wagner Jr., J.R., Mount III, E.M., \& Giles Jr., H.F. (2014). Design of Experiments. In J.R. Wagner Jr., E.M. Mount III, \& H.F. Giles Jr. (Eds.), Extrusion $2^{\text {nd }}$ Edition (pp. 291-308). New York, United States: William Andrew. doi: 10.1016/B978-1-43773481-2.00025-9

World Health Organization. (1998). Quality control methods for medicinal plant materials. Retrieved from

https://apps.who.int/iris/handle/10665/41 986

Yang, Y. \& Deng, J. (2016). Analysis of pharmaceutical products and herbal medicines using ambient mass spectrometry. TrAC Trends in Analytical Chemistry, 82, 68-88. doi: 10.1016/j.trac.2016.04.011

Zambrano, M.V., Dutta, B., Mercer, D.G., MacLean, H.L., \& Touchie, M.F. (2019). Assessment of moisture content measurement methods of dried food products in small-scale operations in developing countries: A review. Trends in Food Science E Technology, 88, 484-496. doi: 10.1016/j.tifs.2019.04.006 